\title{
Erratum to: Ethnic Inequalities in COPD Outcomes: a Register-Based Study in Copenhagen, Denmark
}

\author{
Yusun $\mathrm{Hu}^{1}$ • Lourdes Cantarero-Arévalo ${ }^{1}$ - Anne Frølich ${ }^{2}$ • Ramune Jacobsen ${ }^{2,3}$
}

Published online: 2 February 2017

(C) W. Montague Cobb-NMA Health Institute 2017

Erratum to: J. Racial and Ethnic Health Disparities

DOI 10.1007/s40615-016-0321-1

In the Acknowledgements section, the text at the end of the paragraph "and Helle Wallach-Kildemoes from the University of Copenhagen for the inputs during the manuscript preparation." should read "and Helle Wallach-Kildemoes from the University of Copenhagen for important methodological advice under the preparation of the study".

The online version of the original article can be found at http://dx.doi. org/10.1007/s40615-016-0321-1.

$\triangle$ Ramune Jacobsen

ramune.jacobsen@regionh.dk

1 Section for Social and Clinical Pharmacy, Department of Pharmacy, Faculty of Health and Medical Sciences, University of Copenhagen, Copenhagen, Denmark

2 Research Unit for Chronic Conditions, Hospital Bispebjerg and Frederiksberg, Copenhagen University, Copenhagen, Denmark

3 Research Unit for Dietary Studies, The Parker Institute, Copenhagen University Hospital Bispebjerg and Frederiksberg, Nordre Fasanvej 57, 2000 Frederiksberg, Denmark 